Apollo: Learning From the Past, For the Future

NASA's Constellation program, the successor to the Space Shuttle program, proposes a return to the Moon using a new generation of vehicles. The Orion Crew Vehicle and the Altair Lunar Lander will use hardware and techniques descended and derived from both Shuttle and the original Apollo lunar landing project. However, the new generation of engineers and managers who will be working with Orion and Altair are largely from the decades following Apollo, and are generally unaware of the hardware and techniques developed in the 1960s. In 2007 a project at NASA's Johnson Space Center was begun to find pertinent Apollo-era documentation and gather it, format it, and present it using modern tools for today's engineers and managers. This "Apollo Mission Familiarization for Constellation Personnel" project has been put onto a web site accessible from any NASA center for those interested in learning "how did we do this during Apollo?"

The first step was to gather the documentation - in most cases, reports and handbooks that were written between the mid-1960s and mid-1970s, and residing in various technical libraries at NASA and elsewhere in scanned electronic format only - and make it available in a central location. In many cases, the original authors left "lessons learned" sections in their reports for future engineers and designers. Next, the various instructors, flight controllers, and other specialists on the team reviewed and summarized the pertinent information using collaborative documentation software (aka "wiki" software), and created short summary briefings using presentation software and captured video. The video briefings, the technical wiki web pages, and the original documents are all available from a single web site, and cover a variety of topics from systems briefs to mission techniques. As the project has developed, its scope has expanded and other related information has been added, such as video presentations by Apollo-era experts, briefings by current lunar scientists ("Moon 101"), and photographs of flight hardware from the Kansas Cosmosphere.

The purpose of the Apollo Mission Familiarization website is to provide training material and reference documentation on the Apollo program for Constellation program personnel. A work in progress, this site focuses on three main areas: spaceflight fundamentals, the lunar environment, and Apollo mission techniques. The ongoing project has high visibility from NASA management and has won high praise from its users. 


\title{
IAC-09-D5.2.2
}

\section{APOLLO: LEARNING FROM THE PAST, FOR THE FUTURE}

\author{
Michael R. Grabois \\ United Space Alliance LLC, Houston, Texas (USA) \\ michael.r.grabois@nasa.gov
}

\begin{abstract}
This paper shares an interesting and unique case study of knowledge capture by the National Aeronautics and Space Administration (NASA), an ongoing project to recapture and make available the lessons learned from the Apollo lunar landing project so that those working on future projects do not have to "reinvent the wheel". NASA's new Constellation program, the successor to the Space Shuttle program, proposes a return to the Moon using a new generation of vehicles. The Orion Crew Vehicle and the Altair Lunar Lander will use hardware, practices, and techniques descended and derived from Apollo, Shuttle and the International Space Station. However, the new generation of engineers and managers who will be working with Orion and Altair are largely from the decades following Apollo, and are likely not well aware of what was developed in the 1960s. In 2006 a project at NASA's Johnson Space Center was begun to find pertinent Apollo-era documentation and gather it, format it, and present it using modern tools for today's engineers and managers. This "Apollo Mission Familiarization for Constellation Personnel" project is accessible via the web from any NASA center for those interested in learning "how did we do this during Apollo?"
\end{abstract}

\section{FULL TEXT}

\section{PROJECT ORIGINS}

Constellation is the name given by the National Aeronautics and Space Administration (NASA) to the program intended to succeed the Space Shuttle as its next-generation space vehicles. The various vehicles in Constellation include the crew vehicle Orion, the lunar lander Altair, and the launcher Ares. With the similarity in form and function of the Constellation vehicles to the Apollo program the late 1960s and early 1970s, a proposal was made by the Constellation Program Manager to review the old documentation to see what is relevant in today's space program, rather than "reinventing the wheel" for mission techniques.

The vast majority of Apollo-era engineers who are with the space program today are the agency's senior managers and leaders, and the rank-and-file NASA and contractor engineers and middle managers have gained their experience only with the Space Shuttle or International Space Station. Consequently, few have working knowledge of Apollo hardware, practices, and mission techniques that may prove useful in the Constellation program.

In late 2006, the Constellation Program Manager at the Johnson Space Center (JSC) requested some Mission Operations Directorate (MOD) personnel to form a team with three tasks: to create generic training material on the fundamentals of spaceflight, to turn the old Apollo Mission Techniques documents into lessons on the basics of flying to the Moon and back, and to establish training materials for engineers on the lunar environment. This project should be made available to the NASA community (those behind the NASA Internet firewall) in a distance learning format. The original intent was to focus more on the "what" and "why" than the "how".

The project manager for the "Apollo Lessons Learned" Knowledge Management task, as it came to be known, created a team of volunteers from within MOD, consisting primarily of senior Space Shuttle instructors and flight controllers. Some of the flight controllers were Apollo veterans with first-hand knowledge of Apollo systems. The team members would use their knowledge of Shuttle systems to understand the corresponding Apollo systems, with topics such as electrical and environmental control systems, engines and propulsion, rendezvous, communications, extra-vehicular activities (EVA) and lunar surface operations, and guidance/navigation/control (GNC). 
In most cases, the Apollo mission reports and handbooks were written between 1965 and 1975 , and the original authors frequently left "lessons learned" sections in their reports for future engineers and designers. However, there was no follow-up planned, and limited effort had been made since the creation of the documents to assemble a comprehensive archive of these lessons.

Nevertheless, the documents contained information on the problems and limitations of the hardware, software, and techniques that needed to be brought out. The Project sought to determine how these limitations drove mission technique design.

\section{OBTAINING AND PREPARING THE ORIGINAL MATERIAL}

\section{Documents}

Critical to developing the lessons was having the original source material - the various Apollo Familiarization Manuals, Experience Reports, Operations Handbooks, Mission Techniques, and graphics/photos - available to the researchers. There was no single resource (library or web site) that had all of the desired documentation.

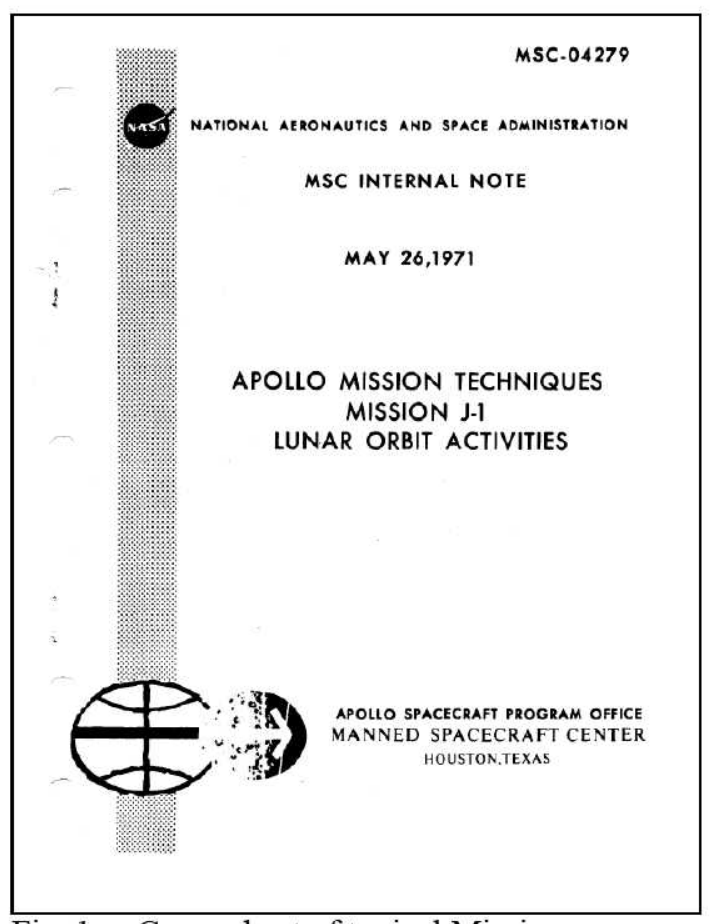

Fig. 1: Cover sheet of typical Mission Techniques document
Figure 1 shows the cover to a typical document, this particular one presenting the guidance and navigation sequence of events, data flow, and real-time decisions for the Mission J-1 (Apollo 15) lunar orbit activities.

The JSC Technical Library was the first location chosen for searching. Many documents were not available in Portable Document Format (pdf) via download from the library's website. Turnaround time for those documents which were not immediately available, and were requested via email, was less than a day for the documents that had already been scanned, and up to two weeks for documents that had not yet been scanned. Many of the documents from the JSC library had International Traffic in Arms Regulation (ITAR) covers, and most had been marked with declassification stamps.

Only documents obtained from the JSC Technical Library had ITAR covers. Copies of identical manuals downloaded from other government-maintained web sites, such as the NASA History Office's Apollo Lunar Surface Journal (ALSJ, at http://history.nasa.gov/alsj/frame.html) and the NASA Technical Reports Server (http://ntrs.nasa.gov/search.jsp), did not. ALSJ has many documents available for public download without an ITAR cover that, when requested from the JSC library, do have ITAR covers. All documents were saved off to a local document repository.

Some documents were obtained from private individuals (such as amateur and semiprofessional space historians) who were contacted directly and who have made the files available online for download via the web (Andrepont, 2008) or offline via Digital Video Disc (DVD). Other documents were obtained from several web-based projects dedicated to explanation and emulation of the Apollo Guidance Computer (Brown, 2003; Burkey, 2009; Katz, 2006). Most of these files had been previously obtained in person from the National Archives and Records Administration (NARA) by those individuals, as there was no publicly available downloading capability from NARA.

Of those documents that did not exist in easilyobtainable electronic format, the JSC library was able to scan many from original paper copies or from microfiche. The microfiche copies were consistently of much lower quality than the 
modern scans and appeared to have gone through several generations of photocopying before being scanned for fiche.

For ease of searching and copying text, all of the documents were processed through Adobe Acrobat, a commercially-available Optical Character Recognition (OCR) software package. Full licenses were available to members of the project team who then processed the files. The publicly available documents had been inconsistently OCR processed, while none of the JSC library files had been OCR processed.

\section{Photographs and Drawings}

In addition to the Manuals and Reports, the research team obtained photographs, schematics, and drawings from a number of sources, including NASA's online photo archives and private enthusiasts. Some schematics and drawings were cleaned up, enhanced, and/or colored using various graphics programs from Microsoft Paint to Adobe Photoshop.

The JSC Photography Branch and the Still Imagery Repository provided requested electronic photos showing hardware and closeout photos.

The Kansas Cosmosphere in Hutchinson, Kansas was very helpful in providing photos for the project from their hardware on display, including the Apollo 13 Command Module (CM) Odyssey and a Lunar Lander mockup. The Cosmosphere obtained permission from the Smithsonian Institution's National Air and Space Museum to open up the sealed CM and photograph panels and switches for use in this project free of charge, in exchange for an acknowledgement credit in any briefing material which used their photos. Figure 2 shows a typical photo taken by the staff at the Cosmosphere for this project.

In other cases, personal photographs found on the Internet were desired. The copyright owners were contacted and all were cooperative, permitting NASA to use their work for Governmental purposes without the payment of a license fee, provided their copyright notice was included beside the image and included a statement that its use was with their permission.

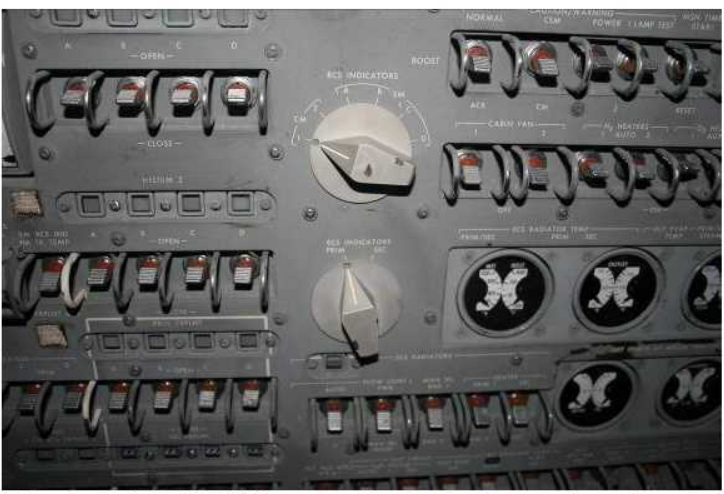

Fig. 2: Typical Kansas Cosmosphere, showing panel $\mathrm{O} 2$ in the Apollo 13 Command Module Odyssey.

\section{CHOOSING AND USING SOFTWARE}

The Apollo Lessons Learned project was designed to be an Internet-based distancelearning experience, but behind a NASA firewall such that users could only access the web site from any NASA facility and authorized contractor sites across the United States.

The target student was defined as someone who is technical and familiar with the space program, most likely a veteran of the Shuttle program who wants more information on Apollo techniques and systems. The typical student could be either an engineer or a manager.

The project manager investigated various options for capturing the lesson content and presenting it to the student, ultimately deciding on a twoprong approach: streaming video lessons for short overview-level briefings, and static web pages for longer, more detailed descriptions.

Collaborative media software allows several concurrent users to create and manage information in a website. For the Apollo Lessons Learned project, a collaborative project management tool was desired that could create a "wiki" site; a wiki is a set of interlinked web pages created and managed with software that tracks changes, has revision control, and allows registered users to edit any page. The project manager also desired a calendar to schedule group meetings and notify project members when information is updated.

The project was given a headcount budget, but little additional budget for software to produce the video briefing content or the detailed web 
pages. Thus, software that was either free or already licensed was the overriding factor.

To stay within the limited budget, the free version of Microsoft's SharePoint v3.0 was chosen for the collaborative media software. Other collaborative software such as Windchill (by Parametric Technology Corporation) and Confluence (by Atlassian) were considered as they were being used in some Constellation projects, but only users who were already firewalled for Constellation could access the software. Not all of the lesson developers were cleared, so the decision was made to use SharePoint.

The original plan for document storage was to use SharePoint's capability, but two factors worked against that: too many documents, and the web server had limitations that prevented large files (frequently over $50 \mathrm{MB}$ (megabytes), with the largest at over $470 \mathrm{MB}$ ) from loading. Instead, the $20 \mathrm{~GB}$ (gigabyte) archive was temporarily housed on some users' desktop personal computers until dedicated space was allocated on an internal network. Currently, a number of the documents are on the SharePoint server but the majority of them are archived on a separate server. Only the users who obtained and OCR-processed the documents have writecapability on the server, everyone else has readonly capability.

For video content, MOD has been using the free Microsoft Producer to create streaming video lessons for the International Space Station (ISS) program for several years. For the Apollo Lessons Learned project, Producer 2007 software was chosen over other commercial products because of its unique ability to replicate in its streaming format the complex PowerPoint 2007 animations created in many of the Apollo lessons. Industry leaders Sonic Foundry's Mediasite and Adobe's Connect Presenter were only able to capture simple animations. The Producer software also allows for customization, allowing the design team to create a fully customized online template with enhanced student features. See Figure 3 for a typical video lesson.

Lesson content created with Producer can be played from the beginning or from any section of the presentation by selecting the desired topic from the index above the video window. The video always remains synchronized with the associated slides. Also provided are links to the home page, help page, instructor's e-mail, references, and with selected lessons, instructor biography.

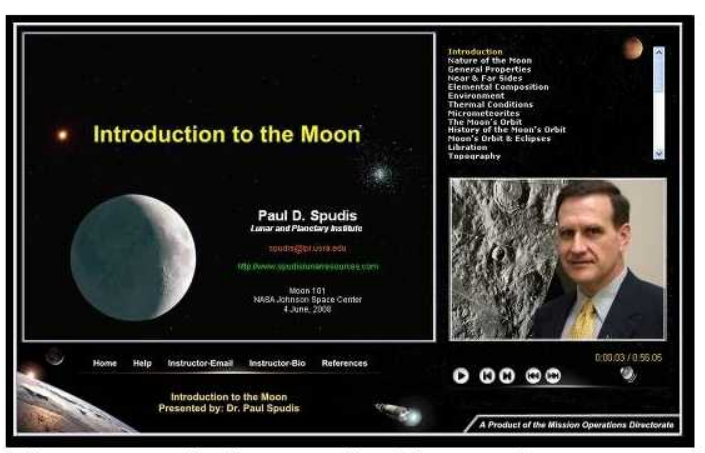

Fig. 3: Typical customized lesson from Microsoft Producer.

\section{CREATING CONTENT}

The members of the Apollo Lessons Learned team were assigned various systems briefings and mission technique briefings depending on their background. The original documents were written by and for knowledgeable insiders, with many unwritten assumptions including that the reader reasonably understands the systems and techniques being discussed.

The team members used their knowledge of similar or analogous Space Shuttle systems to summarize the appropriate material and create text-based wiki entries, in as much detail as was necessary for a full understanding of the material, and then create video lessons at an overview level with less technical presentation. Meanwhile, other team members focused their attention on major operational steps of flight such as Mission Techniques files.

The use of Shuttle instructors from MOD's Space Flight Training section was greatly beneficial to the project, as they had experience distilling information from technical documents into a lesson briefing for their students (i.e., astronaut crews), and were generally comfortable presenting their lesson on camera. The rule of thumb was to try to make the video lesson briefings less than approximately 40 minutes. Those with material that could not be edited down broke their lessons into two smaller parts for easier viewing.

As the instructors created their wiki pages and video lessons, other topics presented themselves 
as candidates for expansion into a separate lesson (e.g., a case study of the Apollo 13 accident grew out of separate discussions of the electrical power systems of the Lunar Module and Command/Service Module). The Project Manager kept track of schedules and which lessons were complete via a Microsoft Excel spreadsheet. A certain number of lessons (which included the wiki and video briefings) were required by the end of each fiscal year, with several ranked by the Project Manager as higher priority than others, but the team members generally had the freedom to create their topics as they saw fit.

As the project progressed, the scope of the overall content of the project slowly increased. One element of the original three-prong task - to turn old Apollo Mission Techniques documents into lessons on the basics of flying to the Moon and back - had grown to encompass systemslevel lessons as well, with the understanding that it was not possible to explain many techniques without first explaining how the underlying hardware and software works.

Periodically, the Project Manager submitted an announcement in the "JSC Today" daily e-mail sent to all JSC employees explaining the project and inviting users to visit the web site. With exposure to the NASA community outside of the project, other groups volunteered to share their Moon-related documents with the Apollo Lessons Learned project to further the project's mandate. The video developers recorded a series of briefings by Moon experts from various institutions (including NASA's Johnson Space Center, The Lunar and Planetary Institute, The Johns Hopkins University Applied Physics Laboratory, and others affiliated with the Constellation Lunar Surface Systems Project Office) called "Moon 101", with topics ranging from the physiography and geology of the Moon to lunar meteorites, and after processing them through Microsoft Producer, incorporated them into the Apollo Lessons Learned material.

Similarly, MOD's Flight Design and Dynamics Department offered their previously-recorded briefings on Apollo GNC and mission techniques such as launch window determination, lunar rendezvous, lunar orbit navigation, and powered descent. These, too, were processed through Producer and made available via links on the web site.
The Fundamentals of Spaceflight section provides links to training materials that provide entry level understanding of spaceflight and orbital mechanics. It provides links to information from NASA's Goddard Space Flight Center and the Jet Propulsion Laboratory, and orbital mechanics computer-based training and distant learning lessons from JSC.

\section{FINISHED PROJECT}

Approximately 40 people were involved in the creation of the material that makes up the website "Apollo: Learning From the Past, For the Future." The original three-pronged mandate for this project has been successfully fulfilled:

- The fundamentals of spaceflight is a main topic on the Apollo Training Materials page.

- The old Apollo Mission Techniques documents, as well as the technical documents on the various spacecraft systems, have been turned into lessons on the basics of flying to the Moon and back. The team created 47 video lessons with a total running time of over 26 hours, and produced 345 pages of content in the wiki.

- Training materials for engineers on the lunar environment have been established, starting with video lessons by lunar experts from the greater NASA community. The lunar expert briefings and Flight Design lessons contributed another 18 lessons lasting nearly 17 hours.

Figure 4 shows the Apollo Training Materials web page. The links go to top-level pages for the different sections of the project:

- Apollo Wiki

- Apollo Systems Lessons

- Case Studies

- Fundamentals of Spaceflight

- Apollo Mission Techniques

- Moon 101 Lunch \& Learn series

- External Sources

- Flight Design Apollo briefings 


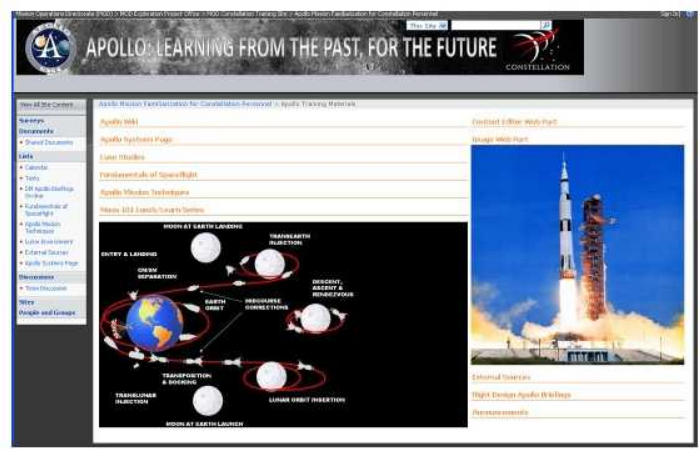

Fig. 4: Apollo Training Materials page

The Apollo Wiki, as seen in Figure 5, contains links to the following sections:

- Vehicle Familiarization pages for Saturn launch vehicle family, the Command \& Service Module, and the Lunar Module

- Mission Techniques (from launch to lunar surface to recovery operations)

- Lunar Environment

- Special Topics

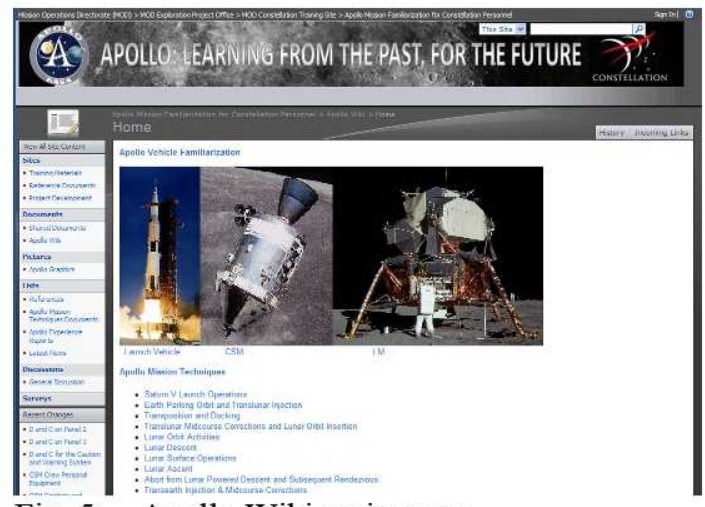

Fig. 5: Apollo Wiki main page

Figure 6 shows the main wiki page for the Command \& Service Module (CSM). Topics include Guidance and Control, Reaction Control System, Docking and Transfer, and Failure Modes and Failure History. Similar pages exist for the Saturn and the Lunar Module vehicles, and each page may have several further subtopic links.

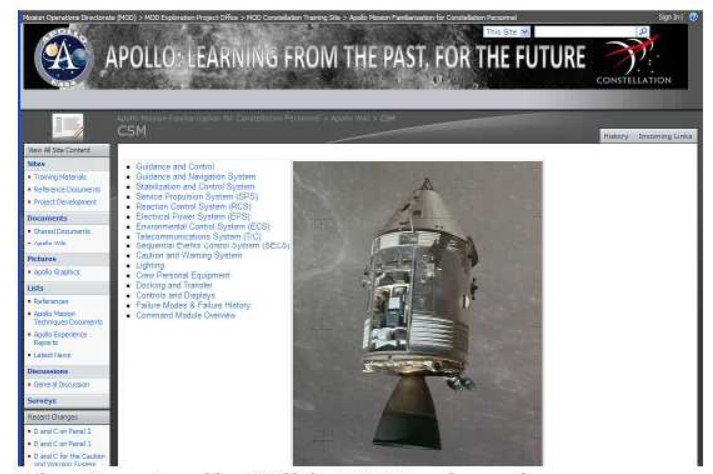

Fig. 6: Apollo Wiki, CSM subsection

From the main Apollo Training Materials page, the user may select the Apollo Systems Lessons page, as seen in Figure 7. This page has links to the various video/PowerPoint lessons on topics such as Displays \& Controls, Electrical, ECLSS, Saturn V, Case Studies, Comm, GNC, and Propulsion.

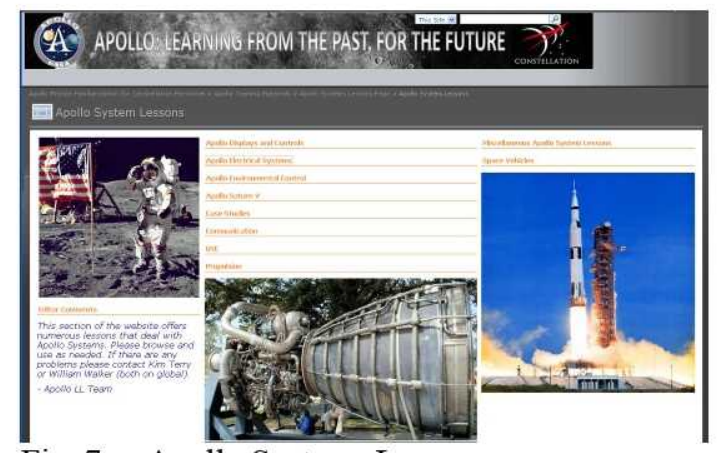

Fig. 7: Apollo Systems Lessons page

The distance-learning lessons are in the form of a recorded briefing by an instructor and the accompanying PowerPoint slides, as seen in Figure 8.

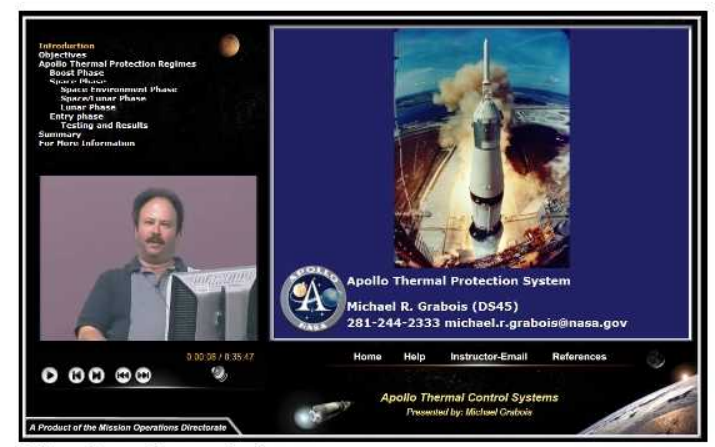

Fig. 8: Sample lesson 


\section{THE FUTURE OF THE PROJECT}

During its two years of existence so far, the Apollo Lessons Learned project has had high visibility from NASA management and has won high praise from its users. In October 2008, the group and project members were presented with a NASA Group Achievement Award "in recognition of the exemplary work of the Apollo Lesson Team who led the development and creation of the Apollo Mission Lessons."

The Apollo Lessons Learned project, as it exists today, is scheduled to be unfunded at the end of Fiscal Year 2009 (October 1, 2009), with the work that has already been done remaining in place. With the success of this project in the nationwide NASA community, the effort in knowledge capture may turn to the future rather than the past. It is possible that a similar lessons learned project for the Constellation program may be implemented so that knowledge capture can be an ongoing effort for contemporaneous material as opposed to (or in addition to) capturing the past. The decision-makers and the tradeoffs that have been made so far may be able to contribute material that would otherwise go undocumented in the typical day-to-day activities.

\section{$\underline{\text { CONCLUSIONS }}$}

The various team members of the Apollo Lessons Learned project reviewed and summarized the pertinent information from the 1960s-1970s era Mission and Systems Reports using web-based collaborative documentation ("wiki") software, and created short summary briefings using presentation software and captured video. The original and new material is available via hyperlinks from the project's main web site. Additionally, newly-added materials such as lectures by Apollo-era experts and briefings by lunar scientists originally outside the scope of the project have been added.

The Apollo Mission Familiarization website provides training material and reference documentation on the Apollo program for Constellation program personnel. This site focuses on three main areas: space flight fundamentals, the lunar environment, and Apollo systems and mission techniques.

Copyright (C) 2009 by United Space Alliance, $L L C$. These materials are sponsored by the
National Aeronautics and Space Administration under Contract NNJ06VA01C. The U.S. Government retains a paid-up, nonexclusive, irrevocable worldwide license in such materials to reproduce, prepare, derivative works, distribute copies to the public, and perform publicly and display publicly, by or on behalf of the U.S. Government. All other rights are reserved by the copyright owner.

BIBLIOGRAPHY

Andrepont, B. (2008, February 2). Manned Spaceflight PDF Documents. Retrieved August 3, 2009, from

http://www.geocities.com/bobandrepont/spacepd f.htm

Brown, A. (2003, February 1). Apollo Guidance Computer Project Home Page. Retrieved August 3, 2009, from History of Recent Science \& Technology:

http://authors.library.caltech.edu/5456/1/hrst.mit. edu/hrs/apollo/public/index.html

Burkey, R. (2009, July 22). Virtual $A G C$ and AGS Home Page. Retrieved August 3, 2009, from http://www.ibiblio.org/apollo/

Jones, E. M., \& Glover, K. (2009, June 25). Apollo Lunar Surface Journal. Retrieved August 3, 2009, from

http:/history.nasa.gov/alsj/frame.html

Katz, R. (2006, April 21). Apollo Guidance Computer and Other Computer History.

Retrieved August 3, 2009, from

http://klabs.org/richcontent/Misc_Content/AGC_ And_History/AGC_History.htm 


\title{
Apollo: Learning From the Past, For the Future
}

\author{
Michael R. Grabois \\ United Space Alliance LLC, Houston TX \\ October 14, 2009
}




\section{Apollo Lessons Learned Project}

- Constellation - back to the moon

- Crew vehicle Orion, lunar lander Altair, launcher Ares

- Knowledge capture

- Current and near future workforce largely unfamiliar with Apollo techniques

- How did we do this during Apollo? Want to prevent having to reinvent the wheel

- Recapture and make available lessons learned from Apollo lunar landing program 


\section{Project Goals}

- Provide training to Constellation personnel

-Fundamentals of Spaceflight

-Apollo Mission Techniques

- Basics of flying to the Moon and back

- Focus on the "what" and "why" over the "how"

- Lunar Environment

- Approximately 40 people involved, primarily Space Shuttle instructors 


\section{Content Creation}

(2)

This content is turned into Wiki pages (using Microsoft SharePoint) that can be used individually for "Justfor-me" training.
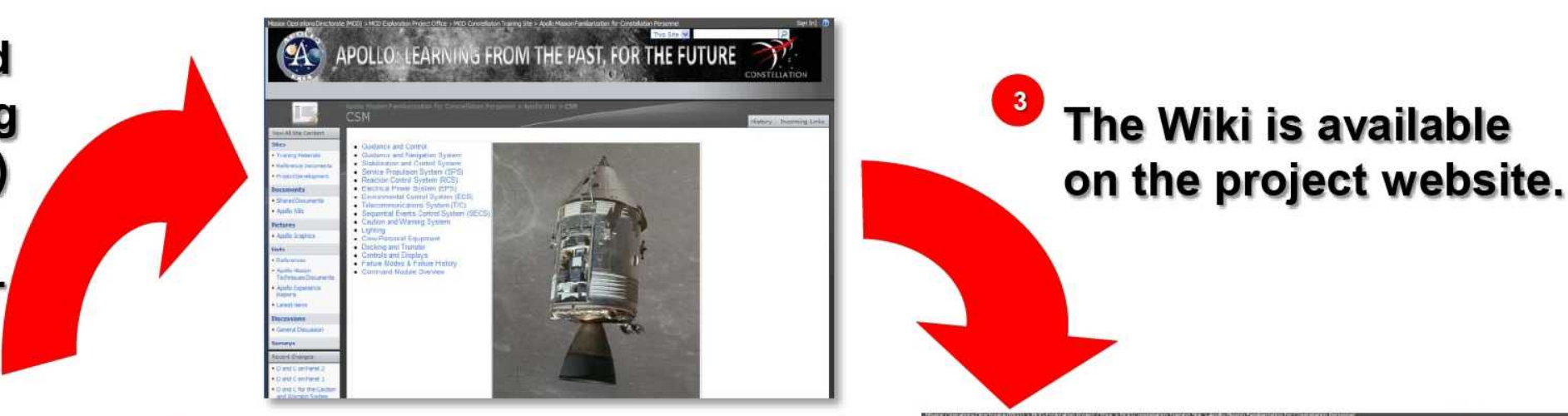

(1)

Instructors study the available documentation to determine what should be taught.

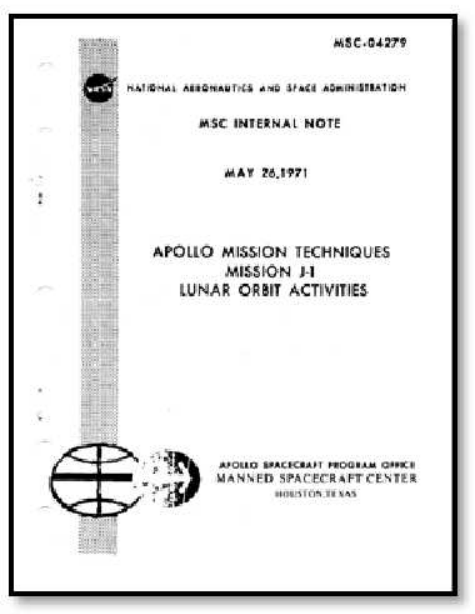

The Wiki content is summarized into standard instructor-led lessons that are then recorded (using Microsoft Producer).

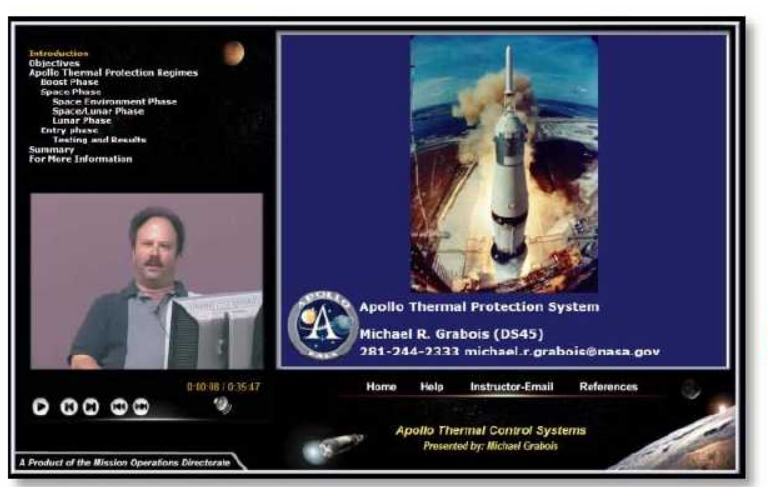

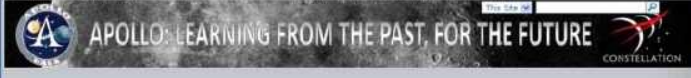
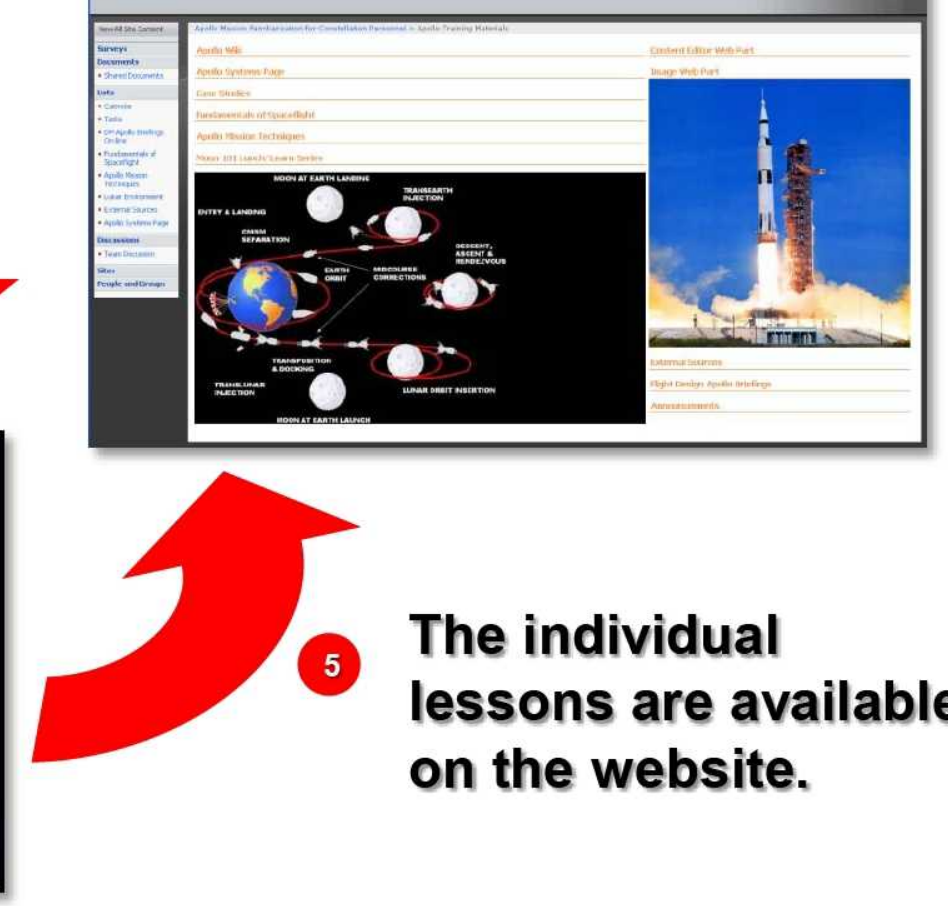

The individual lessons are available on the website. 


\section{Apollo Training Materials site map}

- Apollo Wiki

- Vehicle Familiarization

- Apollo Mission Techniques

- Lunar Environment

- Special Topics

- Apollo Systems Lessons

- Displays \& Controls

- Electrical System

- Environmental Control System

- Saturn V

- Communication

- GNC

- Propulsion

- $\quad$ Case Studies

- Apollo 13 Accident

- Apollo 15 Flight Planning

- Fundamentals of Spaceflight

- Orbital Mechanics CBT

- Basics of Spaceflight

- Apollo Mission Techniques

- Earth Parking Orbit \& Translunar Injection

- Lunar Orbit Activities

- Lunar Descent

- Lunar Surface Operations

- Lunar Powered Ascent

- Apollo Entry

- Recovery Operations
- Moon 101 Lunch \& Learn series

- Moon 101

- Lunar Environment

- Physiography/Geology of the Moon

- Lunar Surface

- Lunar Crust

- Lunar Interior

- Lunar Polar Environment

- External sources

- Virtual Apollo Guidance Computer

- Apollo Familiarization Manuals

- Experience Reports

- Operations Handbooks

- Mission Techniques

- Graphics, photos

- $\quad$ Flight Design Apollo briefings

- Lunar Mission Launch Windows

- Ascent Overview

- Translunar Navigation

- Orbit Insertion/Injection Burns

- Lunar Powered Descent

- Lunar Ascents \& Aborts

- Lunar Rendezvous

- Entry Overview 
Distributed student audience

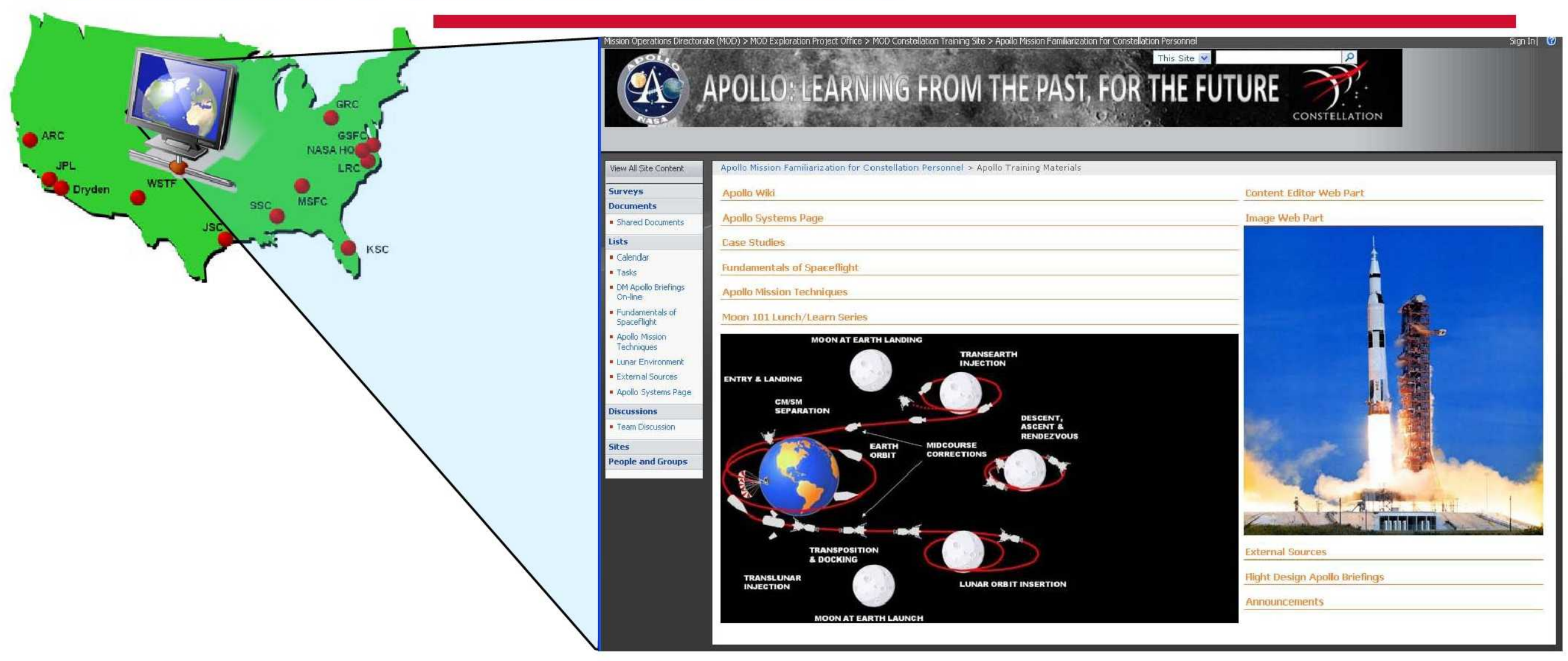

- Live lessons can be given to the JSC audience, but because many Constellation personnel reside at other centers, all training needs to be available electronically 


\section{Apollo Wiki}

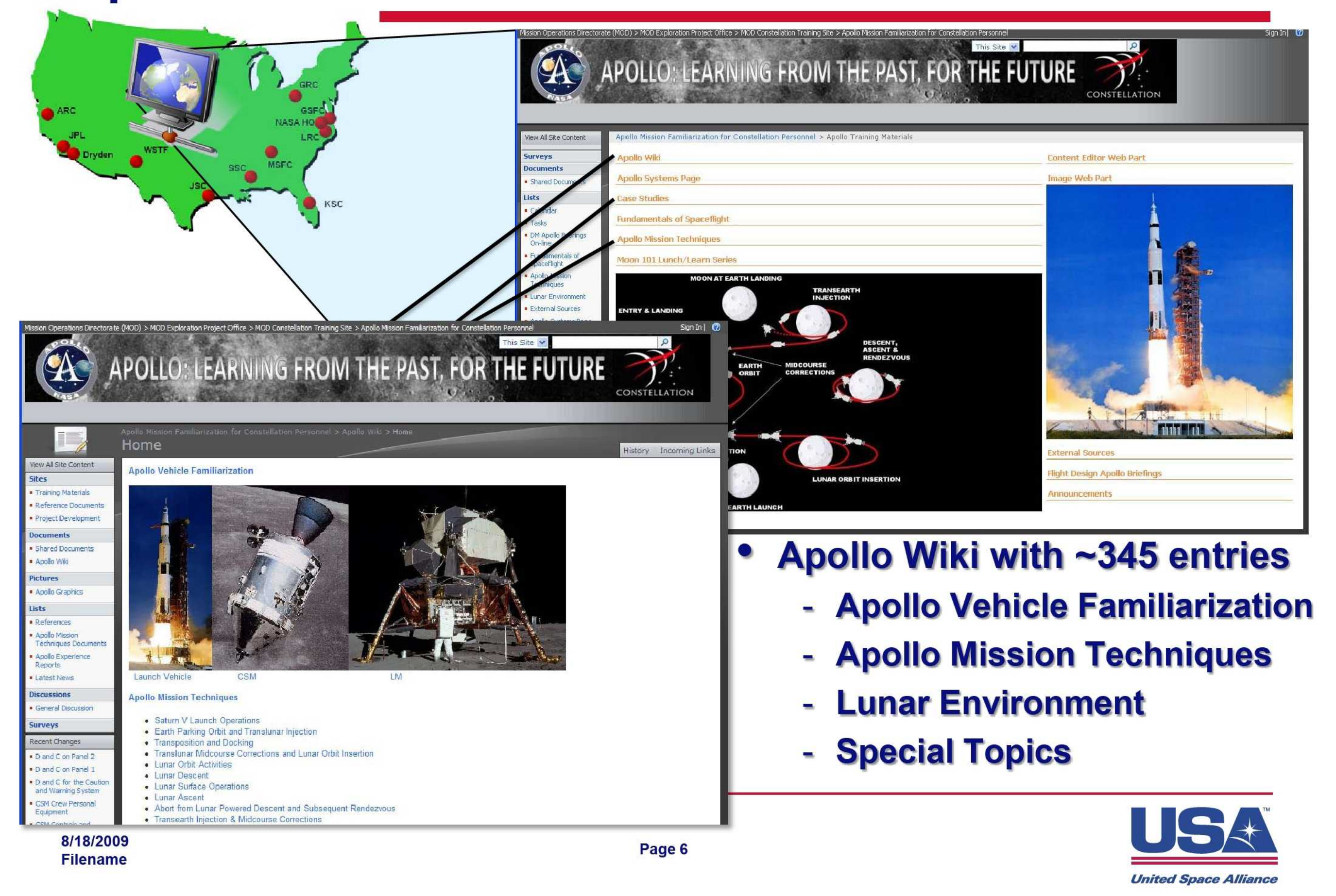




\section{Recorded Lessons}

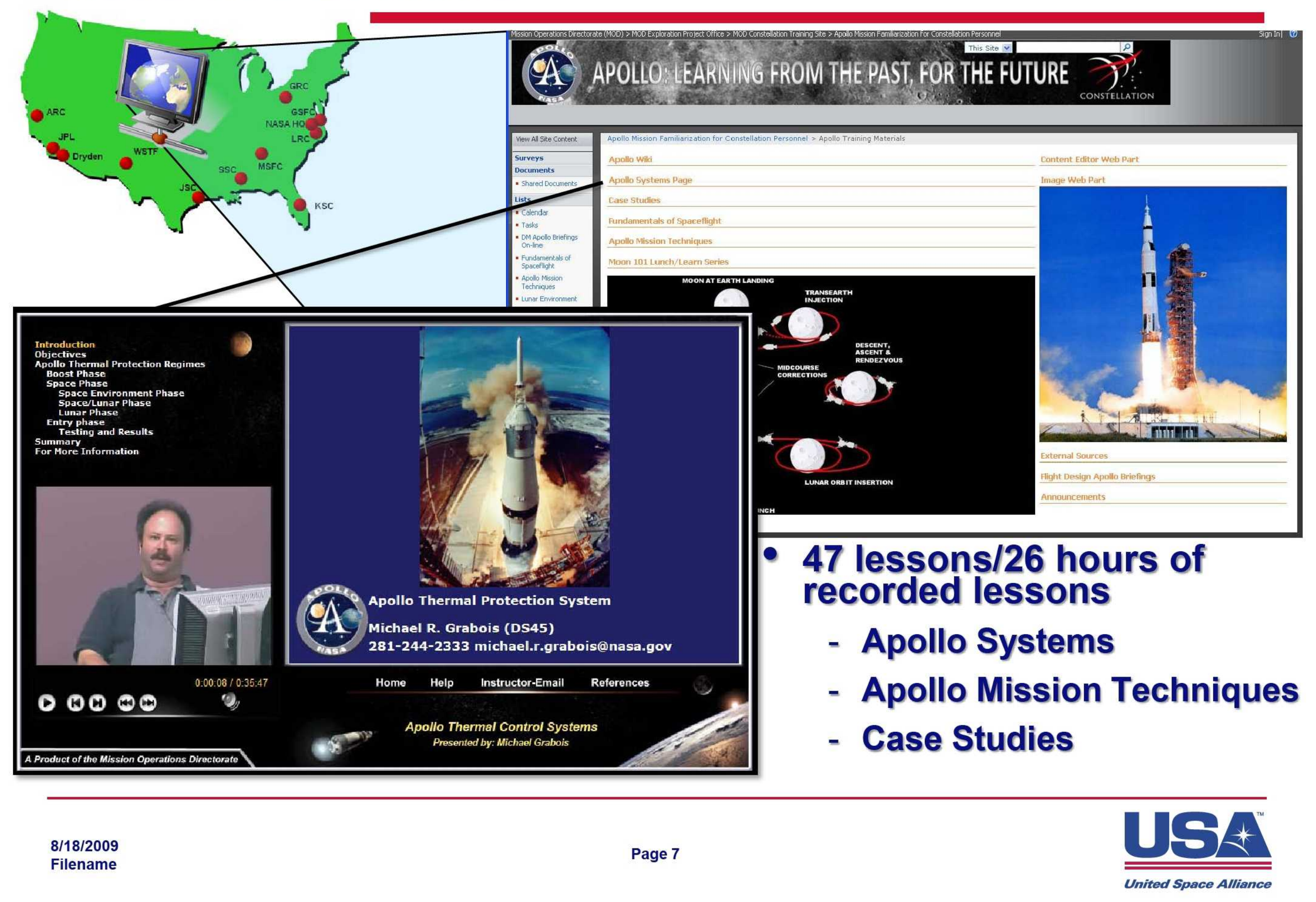




\section{Fundamentals of Spaceflight}

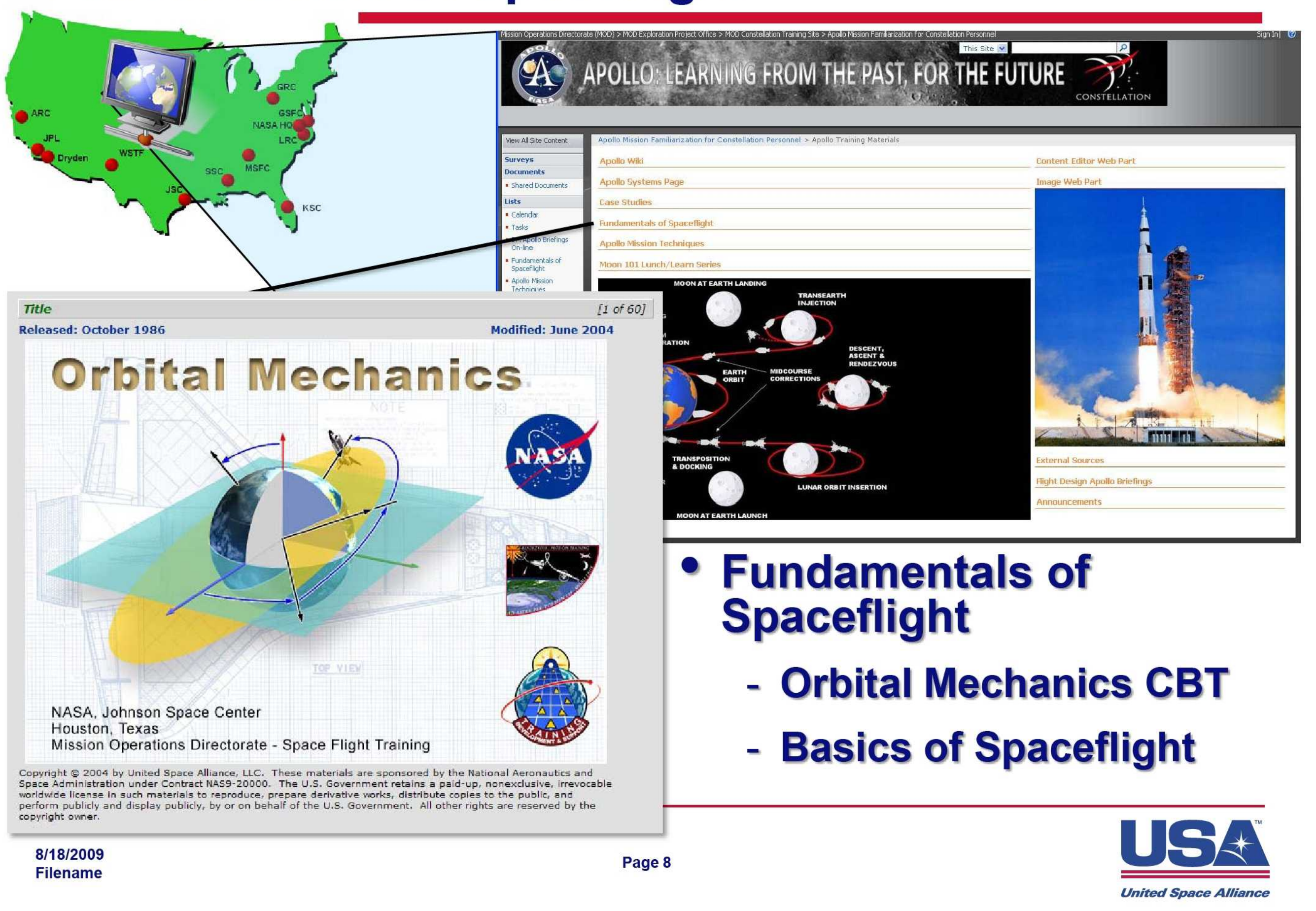




\section{Moon 101}

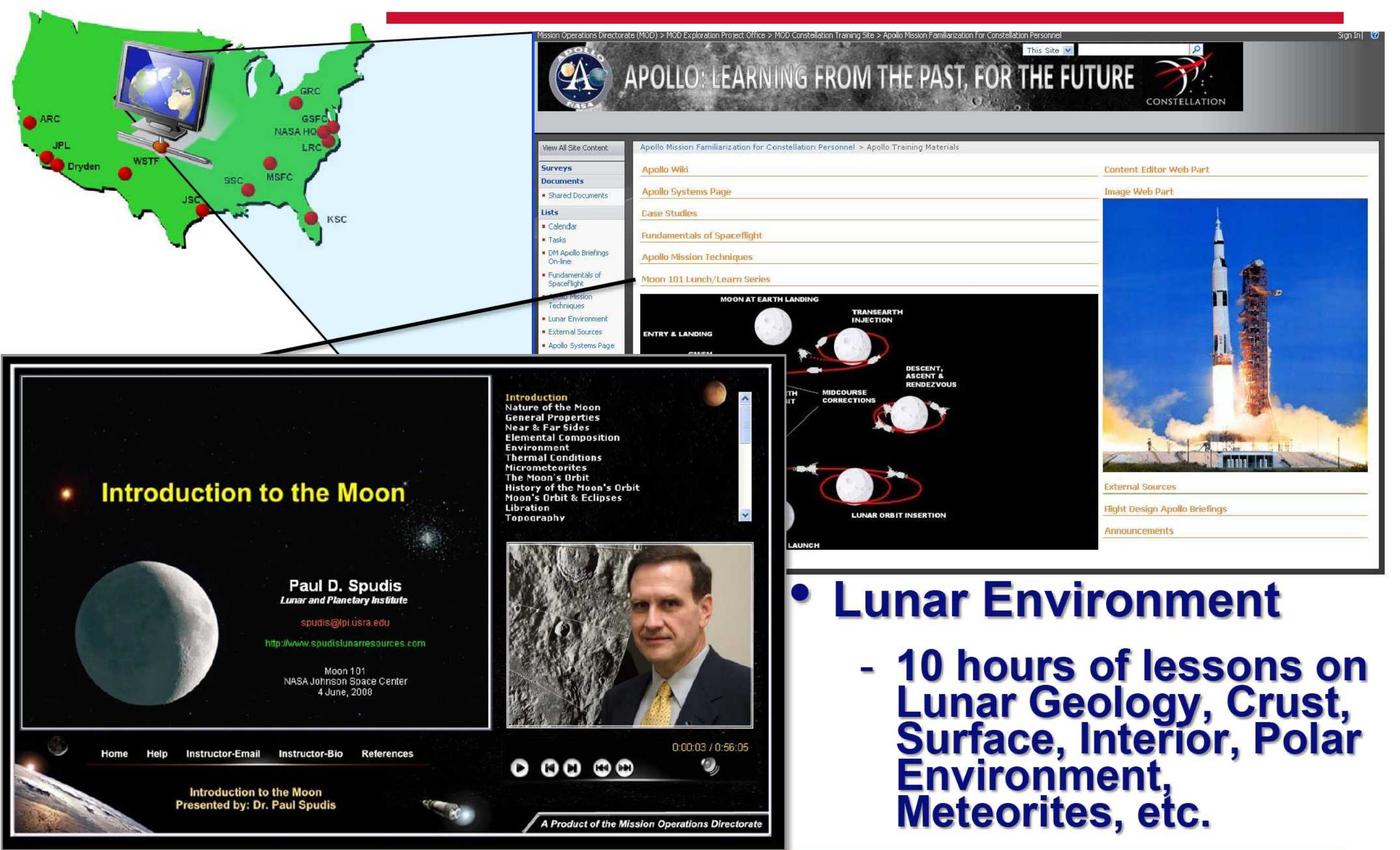




\section{External Sources}

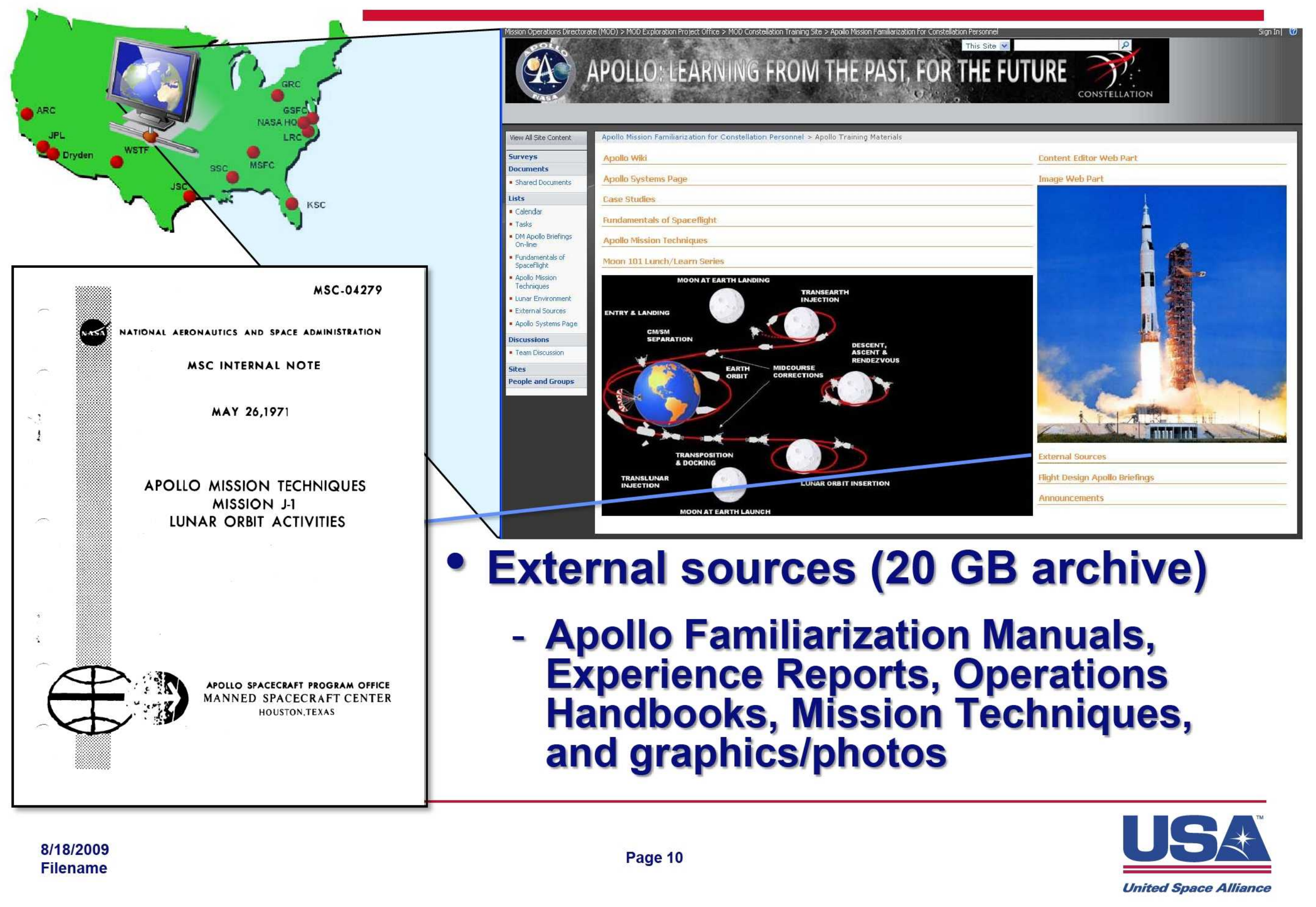




\section{Flight Design \& Dynamics Briefings}

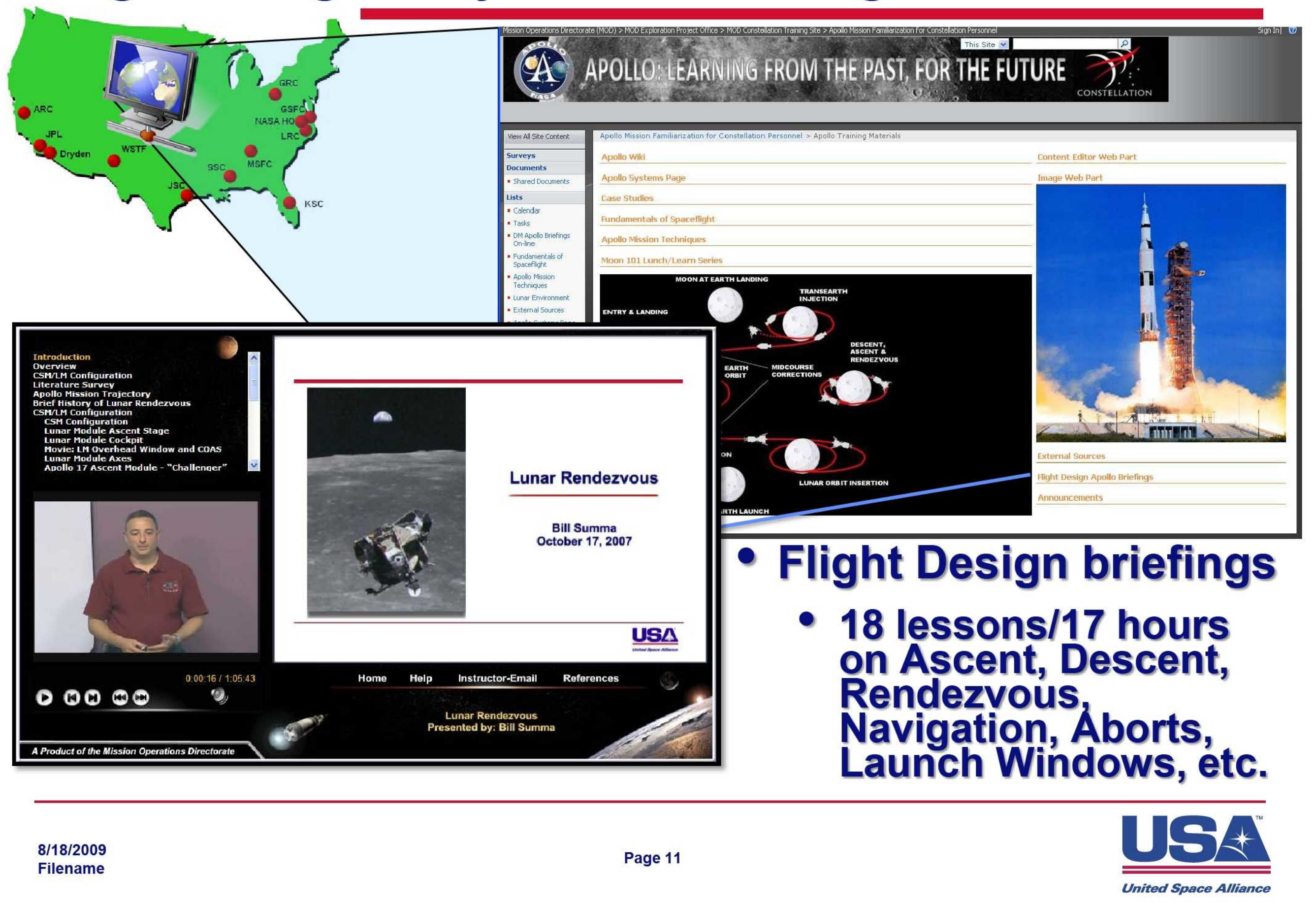


- Apollo Lessons Learned project concluded Sept. 30, 2009

- Proof of concept demonstration

-75 lessons over 53 hours of material

-Use for Shuttle, ISS, and/or Constellation?

- NASA Group Achievement Award to the team 